\title{
El mètode científic aplicat a la caiguda lliure
}

\author{
Ernest Arnau Marco (adjunts@gmail.com) IES Quartó de Portmany (St. Antoni, Eivissa)
}

Partint de l'observació de la caiguda de diferents cossos, ens farem una sèrie de preguntes amb les que analitzarem el moviment i extraurem conclusions. Finalitzarem l'article calculant el valor d'aquesta acceleració utilitzant una gravació del moviment.

Paraules clau: caiguda lliure, g, representació, superposició, equacions del moviment, Logger Pro, mètode científic.

Taking from starting analysis point the free fall of different bodies, a series of different questions will be made through which movement will be analyzed and conclusions will be extracted. We will finish the article calculating the value of this acceleration using a movement recording.

Key words: Free fall, g, representation, superposition, movement equations, Logger Pro, scientific method.

\section{INTRODUCCIÓ}

En molts llibres de ciència i física es presenten els conceptes com un acte de fe. La qual cosa ens porta a un aprenentatge de dogmes i creences on res es comprova $i$ tot es basa en els estudis que han realitzat altres persones. Aquest tipus d'estudi crearà futurs "creients" de la ciència; persones més preocupades per memoritzar fórmules que per entendre el seu significat, origen o experiment base.

Un exemple clar és la caiguda lliure que estudiarem en aquest article. Al llarg dels anys en que un alumne cursa l'assignatura de física utilitza el valor $\mathrm{g}=9,8 \mathrm{~m} / \mathrm{s}^{2}$ en centenars (per no dir milers) d'ocasions però pocs són els que s'han plantejat preguntes al respecte o l'han calculat experimentalment.

\section{OBJECTIU}

Al llarg d'aquest article presentarem una observació (caiguda d'un objecte) a partir de la qual extraurem una sèrie de conclusions. Hem dividit l'article en diferents parts. En la primera part ens farem certes qüestions, quina diferència hi ha entre la caiguda d'una ploma i un martell?, dos objectes d'igual volum però diferent massa es comportaran igual?...
Al llarg de la segona farem un pas més en l'estudi de la caiguda lliure i mostrarem un mètode per calcular l'acceleració dels objectes en caiguda lliure. Juntament amb aquest valor obtindrem una superposició de fotografies que mostraran el moviment i una representació gràfica de la posició respecte al temps. Aquest procés ens permetrà practicar ferramentes mostrades a altres assignatures com matemàtiques o informàtica.

\section{PROCEDIMENT I PROPOSTES DUTILITZACIÓ EN L'AULA}

Com ja s'ha indicat en les seccions anteriors dividirem l'article en dues seccions.

\section{Observació i anàlisi de la caiguda lliure.}

El mètode científic comença amb una observació o pregunta; al cas que anem a analitzar soltarem un objecte (peça, guix...). A partir d'aquest fet tant simple ens preguntarem: ha canviat la seva velocitat? òbviament sí, primer tenia velocitat zero i un instant després una velocitat diferent (sempre respecte al nostre sistema de referència). Soltem diferents objectes i en tots els casos l'observació és idèntica, hi ha una acceleració. 
Però tots els objectes en caiguda lliure tindran igual acceleració? Galileu (1564-1642) es va plantejar aquesta pregunta donant lloc al famós experiment/mite de la Torre inclinada de Pisa. El sentit comú, basat en l'experiència quotidiana, sembla contestar amb un rotund NO!. Qui no ha vist caure una fulla o una ploma? Clarament el temps de caiguda és superior al d'un martell soltat d'igual altura. Al fer reflexionar els nostres alumnes sobre aquest fet ràpidament se n'adonen del desplaçament horitzontal per influència de l'aire. Ens trobem amb un problema: el fregament de l'aire, però també amb l'obstacle de saber si hem soltat els dos objectes al mateix temps.

Aquest darrer problema té múltiples solucions, segons la classe. Les més "usuals" i més útils són: empentar-los des de l'extrem d'una taula o col-locar els objectes sobre una superfície plana (un quadern, per exemple) i retirar aquest molt ràpidament. Solucionat el primer problema ens centrem en l'aire. La primera modificació consistiria en realitzar l'experiència en absència d'aire, però com fer-ho? Els laboratoris dels I.E.S no tenen una cambra de buit tant grossa. Descartada la possibilitat de realitzar la caiguda lliure en el buit, proposem minimitzar la influència de l'aire. La solució més senzilla és agafar objectes de diferent massa però de volums semblants. Una de les formes més simples és construir els nostres propis objectes amb pilotes de tennis. A una de les dues pilotes de tennis li farem un forat i emplenarem l'interior d'arròs (també serveix sorra, sucre...). Després recobrirem la superfície de les dues pilotes amb esparadrap de forma que tinguin el mateix volum final. Ja tenim els dos objectes preparats amb masses diferents però ens queda un pas, pintar-les de colors diferents i molt cridaners (Imatge 1). El pintar-les no és important per aquesta part, però com veurem després sí per a realitzar el càlcul de l'acceleració.

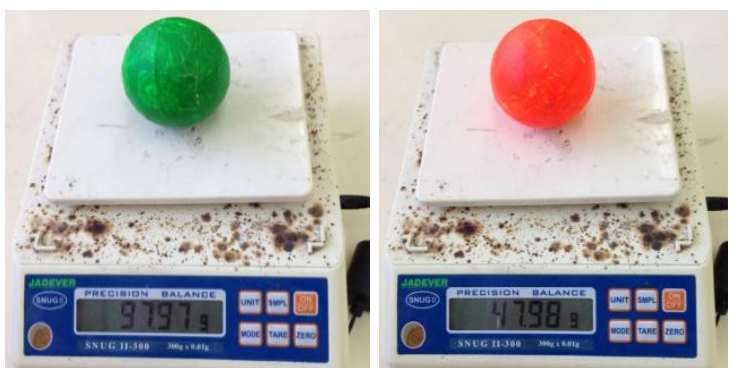

Imatge 1. Mostra de les dues pilotes de tennis preparades. A les imatges podem observar la major massa de la pilota verda $97,97 \mathrm{~g}$ en front dels $47,98 \mathrm{~g}$ de la vermella.
Finalment col-loquem les pilotes de tennis sobre una llibreta i les soltem des d'una altura determinada, haurem de repetir l'experiència per assegurarnos que tots els alumnes han observat el xoc contra el terra. L'observació directa ens permet obtenir una conclusió sorprenent: els objectes de diferents massa recorren espais iguals en temps iguals!

\section{Càlcul de l’acceleració.}

Un cop hem comprovat experimentalment que els cossos de diferent massa s'acceleren igual en caiguda lliure (fet que tornarem a comprovar) procedirem a calcular el seu valor. A la primera part de l'article s'ha indicat com crear un dels materials que utilitzarem (les pilotes de diferents colors, imatge 1) però són necessaris uns altres materials: mínim de 2 metres de paper continu, càmera de fotos/vídeo i un ordinador.

El primer que hem de fer és marcar el paper continu amb separacions, fet que ens servirà per saber en quina posició es troba la pilota en cada instant de la caiguda. En el nostre cas cada 10 centímetres (imatge 2). Una vegada preparat el paper continu sols hem de penjar-lo, començar a gravar i soltar les dues pilotes al mateix temps. Per assegurar-nos que ho fem en al mateix temps utilitzem la llibreta o una altra superfície plana, tal com s'ha indicat en l'apartat anterior. A la Imatge 2 podem observar la posada en pràctica de l'experiència.

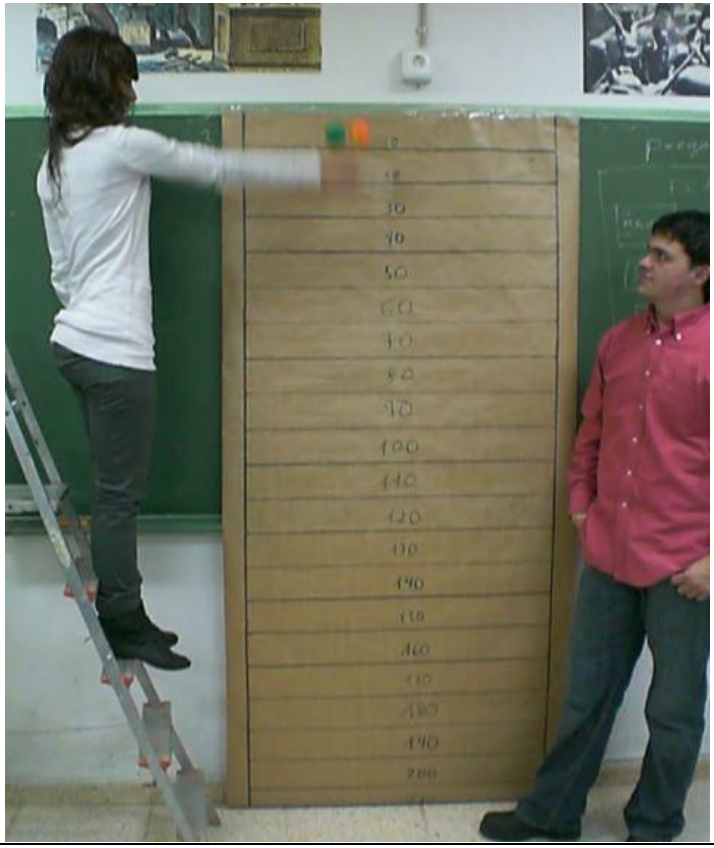

Imatge 2. Fotografia extreta de la gravació experimental. Podem observar l'inici de la caiguda de les dues pilotes i el paper continu. 
Un cop ja tenim la nostra gravació és necessari fer un tractament d'aquesta. A un darrer article (Arnau, 2013) vam descriure com obtenir diferents fotografies d'un vídeo. En dit article (a l'igual que en aquest) l'extracció de les imatges la realitzàrem amb el programari Quicktime Pro i la superposició amb Pixelmator. Amb un llançament de 2 metres hem obtingut una seqüència de 7 imatges amb un interval de $0,1 \mathrm{~s}$ entre fotogrames. La imatge 3 mostra el resultat de superposar, per separat, les imatges de dos gravacions diferents. Aquestes superposicions ens mostren clarament:

- Les dues pilotes (de diferent massa) recorren el mateix espai en temps iguals. Hem comprovat el que hem deduït en la primera part de l'article.

- Hi ha una acceleració constant amb un valor que obtindrem posteriorment.

- Ens permet conèixer les posicions de les pilotes en cada instant. Valors que utilitzarem a continuació per crear una gràfica amb Excel i obtenir el valor de l'acceleració.
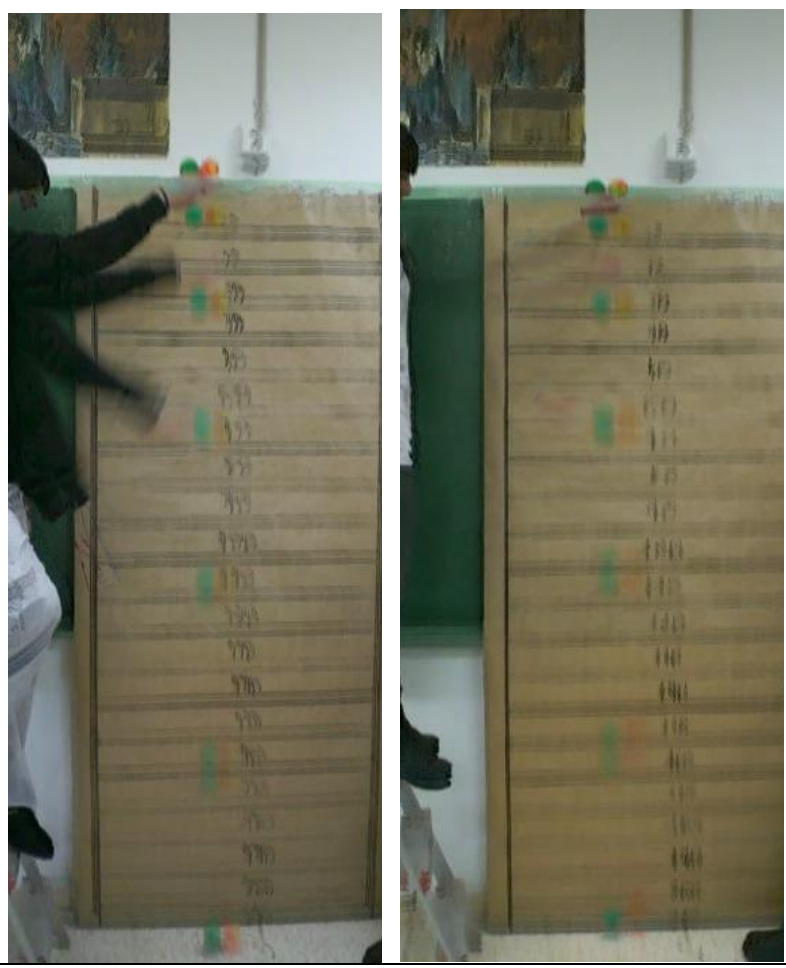

Imatge 3. Superposició de les imatges obtingudes amb dos gravacions diferents i superposades amb el programari "Pixelmator".

Al visualitzar les imatges queda clar el motiu de pintar les pilotes de colors cridaners, la càmera mostra millor la posició.
En aquest punt estem en condicions de calcular el valor de l'acceleració a partir de la gravació. Mostrarem dos procediments:

El primer és utilitzant les imatges que hem superposat i les posicions de la pilota a partir del paper continu. De les imatges de la gravació i per observació directa extraiem la posició en $y$ de la pilota. A continuació representem amb un full Excel la posició y en funció del temps (sabem que el temps entre fotograma és $0,1 \mathrm{~s}$ ). En la gràfica 1 mostrem els valors del grup 1 (grup de l'esquerra de la imatge 3).

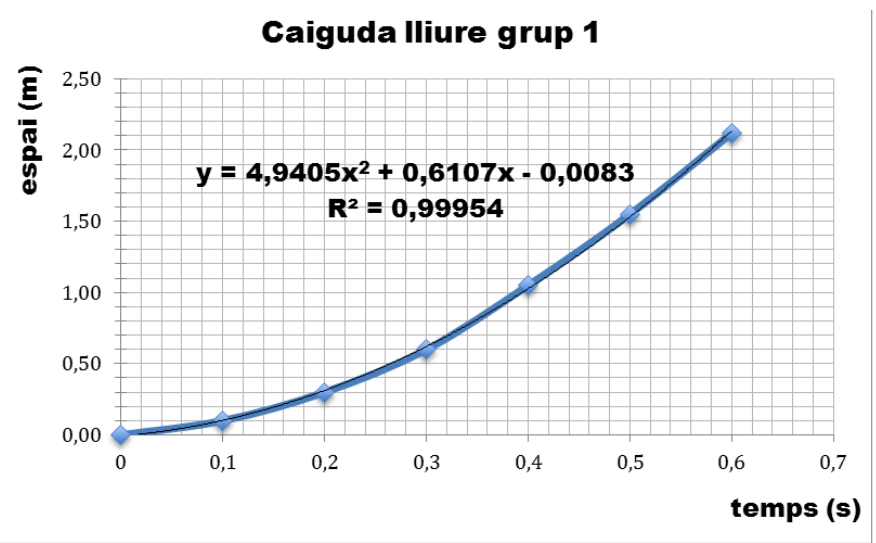

Gràfica 1. Representació dels valors obtinguts del grup 1. Hem demanat a l'Excel que ajusti els punts a una punts a una paràbola $i$ que ens mostri l'equació.

Al representar els valors hem obtingut l'equació que ajusta els punts de la gràfica. A continuació la comparem amb l'equació d'un M.R.U.A:

$y=4,94 x^{2}+0,6107 x \quad 0,0083 \Leftrightarrow y=\frac{1}{2} g \cdot t^{2}+v_{0} \cdot t+y_{0}$

Amb el que podem deduir un valor de $\mathbf{g}=\mathbf{2} \cdot \mathbf{4 , 9 4}$ $=9,88 \mathrm{~m} / \mathrm{s}^{2}$

\section{Utilitzant el programa Logger Pro.}

A l'article (Arnau, 2013) vam explicar com utilitzar aquest programari per obtenir els punts i la representació d'una gravació. En aquest cas utilitzarem la gravació del grup 2 (grup de la dreta de la imatge 3). Després de marcar els punts directament sobre la gravació, el programa ens proporciona la posició tant en $x$ com en $y$ de la pilota però també les velocitats en $x$ i en $y$. Logger Pro permet realitzar la gràfica dels valors desitjats i ens mostra l'equació que els ajusta. 
$y=4,7 x^{2} \quad 0,96 x \quad 0,029 \Leftrightarrow y=\frac{1}{2} g \cdot t^{2}+v_{0} \cdot t+y_{0}$

Amb el que podem deduir un valor de $\mathbf{g}=\mathbf{2} \cdot \mathbf{4 , 7}$ $=9,4 \mathrm{~m} / \mathrm{s}^{2}$

Cal assenyalar que els creadors de Logger Pro disposen d'una versió per al sistema iOS (ipad, iphone, ipod) anomenada "Video Physics". Aquesta App ens permet realitzar el vídeo i l'anàlisi posterior utilitzant sols un dispositiu. Com a darrera activitat podem comparar aquest valor experimental amb el $9,8 \mathrm{~m} / \mathrm{s}^{2}$ dels llibres per fer-nos una darrera qüestió: per què obtenim valors pròxims però diferents? Amb aquesta pregunta ensenyem als nostres alumnes a ser reflexius amb els resultats experimentals i amb els llibres. A més de pensar en formes de millorar l'experiment $i$ en els errors inherents a tot experiment.

\section{BIBLIOGRAFIA}

ARNAU MARCO, E. (2013). Estudi experimental del tir parabòlic. Revista Ciències, 26, 21-23.

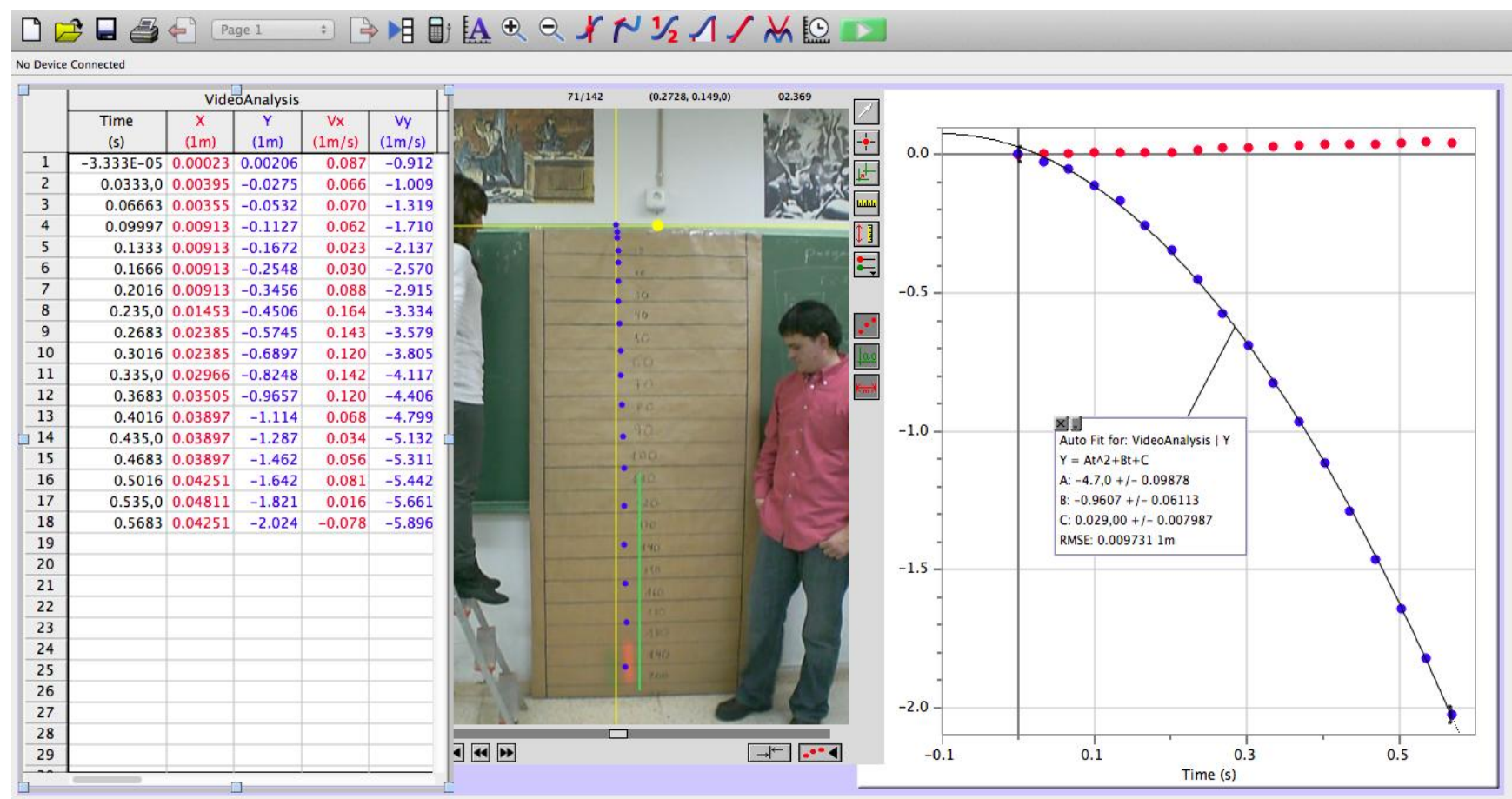

Imatge 4. Captura d'imatge del programa Logger Pro. D'esquerra a dreta: 1. valors a partir de la gravació que extreu el programa; 2 . Selecció de les posicions de la pilota directament del vídeo. 3. Representació dels punts i equació que els ajusta. 